\title{
Jinekolojik Kanserli Kadınların Brakiterapi Sonrası Cinsel İşlevinin Değerlendirilmesi ve Cinsel Danışmanlık
}

Evaluation of Sexual Functions of Women with Gynecological Cancer After

Brachytherapy and Sexual Counselling

\section{Review Article}

\section{Çiğdem Bilge1 ${ }^{1}$ Büşra Yılmaz², Ümran Oskay³}

DOI:

Öz

Cinsellik biyolojik, psikolojik, kişiler arası ve davranışsal boyutları olan çok boyutlu karmaşık bir kavramdır. Ülkemizde oldukça yaygın görülen jinekolojik kanserlerin kadın sağlığı üzerindeki olumsuz etkileri çok boyutludur. Jinekolojik kanser semptomları ve tedavisinin kadın cinsel sağlığı üzerine olumsuz etkileri kadının yaşam kalitesini de etkilemektedir. Jinekolojik kanserler arasında sık görülen servikal kanser tedavisinde kullanılan brakiterapi vaginal stenoz, disparoni, cinsel istekte azalma ve orgazm güçlüğü gibi sorunlara neden olmaktadır. Brakiterapi tedavisi gören hastalar cinsel sorunlarıyla ilgili genellikle etkin danışmanlık alamazlar. Bu konu sağlık profesyonellerinin ihmal ettiği bir konudur ve brakiterapi sonrası kadınlar cinsel işlev bozuklukları ile baş etmeyi kendi kendine öğrenmek zorunda kalır. Bu zorlu süreçte hemşirelere, kadınların cinsel yaşamlarını değerlendirmede, özellikle cinsel danışmanlık ve rehberlikte, modellerin kullanımı önerilmektedir. Anahtar sözcükler: Brakiterapi, Cinsel işlev, Danışmanlık
Geliş/Received : 19.01 .2018

Kabul/Accepted : 09.06.2118

Abstract
Sexuality is a complex concept involving biological,
psychological, interpersonal and behavioural aspects.
The negative effects of gynecologic cancers, which
are quite common in our country, on women's
health are multi-dimensional. The negative impacts
of gynecologic cancer symptoms and treatment on
the woman's sexual health also affect the quality of
her life.
Brachytherapy, used in the treatment of cervical
cancer, which is most common of gynecologic
cancers, causes problems such as vaginal stenosis,
dyspareunia, reduced sexual desire and difficulty in
achieving orgasm. The patients, who undergo
brachytherapy usually cannot get effective
counselling on their sexual problems. This is an
issue, which is neglected by health professionals and
women are obliged to learn to cope with sexual
dysfunction after brachytherapy by themselves. In
this challenging period, nurses should use the
models in assessing the women's sexual lives,
especially in sexual counselling and guidance.
Key words: Brachytherapy sexual Function,
Counselling

1 Arş. Gör. Dr.; Muğla Sıtkı Koçman Ü. Kadın Sağlığı ve Doğum Hemşireliği (Orcid No: 0000-0002-8120-6216)

2 Arş. Gör.; İstanbul Ü. Florence Nightingale Hemşirelik Fak. Kadın Sağlığı ve Hastalıkları Hemşireliği AD.

(Orcid No: 0000-0001-6937-5351)

3 Prof. Dr.; İstanbul Ü. Florence Nightingale Hemşirelik Fak. Kadın Sağlı̆̆ı ve Hastalıkları Hemşireliği AD.

(Orcid No: 0000-0002-6606-9073) 


\section{Giriş}

Cinsellik, doğum öncesinde başlayıp, kişinin değerleri, inanışları, fiziksel görünümü ve yaşadığı kültüre göre biçimlenen bir kavramdır. Cinsellik tüm bedeni ve ruhu içerir. Cinsellik insanın düşünsel, duygusal ve toplumsal bütünlüğünü sağlayan, olumlu yönde kişilik gelişimi, sevgi paylaşımı ve iletişimin görüldüğü sağlıklılık halidir $(1,2)$. Cinsellik ekonomik, sosyal, kültürel, politik, dini, biyolojik ve ruhsal faktörlerin etkileşiminden etkilenmektedir (2). Cinsel işlev bozukluğu ise bireylerde cinsel yanıt döngüsünde bozukluklar ile karakterize, ruhsal ve fiziksel değişikliklere bağlı olarak ortaya çıkan bir durumdur (3).

Jinekolojik kanserler kadın genital organlarında tutulum gösteren kötü huylu oluşumlardır. Jinekolojik kanserlerin semptomları tutulan organa göre farklılık gösterip, bu grupta başlıca endometrium, serviks ve over kanserleri yer almaktadır. Dünyada kanser olgu sayısı her geçen gün artmaktadır. Gelişmekte olan ülkelerde servikal kanser ikinci en çok görülen Jinekolojik kanser türüyken, gelişmiş ülkelerde ise endometriyum kanseri en çok görülen jinekolojik kanser türüdür (4). Türkiye'de, Halk Sağlığı Kurumu'nun 2014 yılındaki kanser istatistiklerine göre, her yıl yaklaşık 63 bin kadına kanser tanısı konulmaktadır. Jinekolojik kanserler ise meme kanserinden sonra mortalite ve morbidite oranı en yüksek olan ikinci kanser türü olarak belirlenmiştir (5).

Jinekolojik kanser semptomları ve tedavisinin cinsel sağılık üzerine etkisi genel olarak göz ardı edilse de cinsellik kadın yaşamının kalitesini artıran bir boyut olarak önemini korumaktadır. Üreme organ kanserleri cinsel sağlığı olumsuz etkilemektedir. Jinekolojik kanserler beden imajı, cinsiyet rolü, kadın kimliği ve üreme yeteneğini etkileyerek cinselliği yaşamayı etkiler (6). Jinekolojik kanser belirtilerinden olan vajinal kanama, halsizlik, karın ağrısı ve postkoidal kanama kadının tedavi öncesi cinsel sağlığını bozmaktadır. Tedavi sonrasında vajinada kısalma, vajinal elastikiyetin bozulması, vajinal lubrikasyonda azalma, vajinal stenoz, klitorisin alınması, pelvik sinir hasarı, fistüller, halsizlik, ishal, uykusuzluk, infertilite ve postkoidal kanama gibi fiziksel belirtiler cinsel sağlığı olumsuz etkilemektedir (7). Üreme işlevinin kaybı, dış görüntüsünün değişmesi, cinsel işlevlerin eskisi gibi yerine getirilememesi ve kendisini kadın gibi hissetmemesi cinsel kimlik algısının değişmesine neden olur (8). Jinekolojik kanser tanı ve tedavisinin cinsel sağlığı olumsuz etkilediğine dair çok sayıda çalışma vardır $(5,6,9,10)$.

Kanser tanısı konulması yeterince zor bir süreç iken, kanser tedavileri de sürece yeni korkular ekler. Jinekolojik kanserlerde uygulanan cerrahi tedavi, radyoterapi ya da kemoterapi kadının beden algısını ve üreme kapasitesini olumsuz yönde etkiler. Hasta ve ailesinin yaşam kalitesinin bozulmasına neden olur (11-13).

\section{Brakiterapi ve Cinsel Yaşama Etkisi}

Radyoterapi tümörlü dokuya radyasyonun vücut dışından direk olarak verilmesini içeren eksternal radyoterapi ya da radyasyonun vücut içerisine, vücut yakınına ya da direkt üstüne konularak uygulanmasıyla gerçekleştirilen yöntem olan brakiterapi şeklinde uygulanır $(14,15)$. Brakiterapi'nin jinekolojik kanserlerin tedavisinde önemli bir yeri vardır. Yunancada 'kısa' anlamına gelen brakiterapi 'brachios' sözcüğünden türetilmiştir. Brakiterapi, radyoaktif kaynağın tümörün içine ya da yakınındaki boşluklara yerleştirilmesiyle uygulanılan bir tedavi şeklidir. Brakiterapi, 1898' de radyumun keşfinden sonra uygulanmaya başlamıştır. Bu tedavi intrakaviter ve interstisyel olmak üzere iki biçimde uygulanır. Intrakaviter brakiterapide aplikatör tümörün yakınındaki anatomik boşluklara yerleştirilir. En sık endometriyum, serviks, vajina ve akciğer kanserinde kullanılır. İnterstisyel brakiterapide ise aplikatör ilgili doku içerisine yerleştirilir. En sık meme, prostat ve yumuşak doku kanserinde kullanılır. Amerikan Brakiterapi Topluluğu (American Brachytherapy Society- ABS), endometriyum ve serviks kanserli hastalara uygulanan radyasyon tedavisi endikasyonları için Ulusal Kapsamlı Kanser Ağı rehberini yayınlanmıştır. Yayınlanan rehberde aplikatör seçimi, brakiterapi aplikatörünün yerleştirme teknikleri, hedef hacim tanımı, doz fraksiyonasyonu ve ameliyat sonrası adjuvan vajinal kaf tedavisi için önemli tavsiyelere yer verilmiştir $(16,17)$.

Brakiterapide amaç, kanser hücrelerinin bölünmesini önleyerek, çoğalmasını engellemek ve yok etmektir. Bu işlem uygulanırken kanser hücrelerinin yanı sıra sağlam hücreler de zarar 
görür. Hücre ölümü ya da tedavi edilebilen hücre hasarı meydana gelebilir. Radyasyonun yan etkileri arasında deri toksisitesi, yorgunluk, bulantı ve kusma görülür $(15,18)$. Kircheinner ve ark. (2015) servikal kanser tedavisinde uygulanan brakiterapinin yaşam kalitesine etkisini incelemişlerdir. Çalışma sonucunda kadınların brakiterapi sonrası yorgunluk (\% 78), üriner inkontinans (\%60), bulantı ve kusma (\%54), sıcak basması (\% 44) ve cinsel işlev bozukluğu (\%38) yaşadığı belirtilmiş̧ir (19).

Brakiterapinin cinsel sağlık üzerine etkisi genel olarak göz ardı edilse de cinsellik kadın yaşamının kalitesini artıran bir boyut olarak önemini korumaktadır. Erken evre endometriyum ve serviks kanserinde primer olarak uygulanan brakiterapi esnasında vajinal atrofi, sinir hasarı ve fibrozis gelişebilir (20). Tedavi esnasında over fonksiyonları da etkilenir ve overlerde steriliteye sebep olur. Vajina epitelinde ise elastikiyet kaybı, eritem, atrofi ve inflamasyon görülür. Işınlama sonucunda vajinada kuruluk ve daralma meydana gelir. Bu durumda vajina bölgesi enfeksiyon ve travma açısından daha fazla risk altındadır. Vajinadaki tüm bu değişimler sonucunda orgazm problemleri, elastikiyetin azalması ve disparoni en sık görülen şikayetler arasındadır. Bu yan etkiler ilk üç ay içinde oluşmakta ve bir yıl içerisinde düzelmektedir (21). Karabuga ve ark. (2015) endometrium kanseri tedavisinde eksternal radyoterapi ve vajinal brakiterapi alan kadınların cinsel fonksiyon ve yaşam kaliteleri karşılaştırmışlardır. Çalışma sonucunda her iki tedavi şeklinin de cinsel fonksiyonları ve kadınların yaşam kalitelerini olumsuz etkilediği bulunmuştur (22).

\section{Kadınların Cinsel İşlevinin Değerlendirilmesi ve Cinsel Danışmanlık}

Cinsellik, çok boyutlu bir kavramdır ve brakiterapiden olumsuz yönde etkilenmektedir (5, 10, 23). Brakiterapinin yanısıra kadın, kadınlık kimliğini, değerlerini, önceliklerini ve cinsel partner sorumluluğunu yeniden kazanma çabası içerisindedir. Böyle bir süreçte, destek sistemleri ve danışmanlık hizmetleri kaygı ve endişeleri gidermede önemli rol oynamaktadır (24). So ve Chui (2007) kadınların brakiterapi sonrası yaşadıkları deneyimleri incelemek amacıyla yaptıkları nitel çalışma sonucunda barkiterapi sonrası psikolojik destek sağlama, işlem öncesi ve sonrasında açıklama ve bilgilendirmenin önemli olduğu vurgulanmıştır (25).

\section{Brakiterapinin Kadın Cinselliğine Etkisi ve Vajinal Dilatatör Kullanımı}

Brakiterapi vajinanın daralmasına ve labia majörlerin birbirine yapışmasına neden olur. Vajinal dilatörler, brakiterapi sonrası vajinada kısalma ve darlıkları önlemek için ek yöntem olarak kullanılır. Cinsel yaşamlarında başarısız olan ya da kendini yetersiz hisseden kadınların bu sorunlarla baş edebilmeleri için vajinal dilatatörlerin kullanılması önerilmektedir $(26,27)$.

Brakiterapiden sonra vajinal dilatatörlerin düzenli kullanımı rutin uygulanır hale gelmiştir.

Uygulamada üçgen şeklindeki bir aletin vajene sokulması ve döndürülmesi gerekir. Haftada en az birkaç kez yaklaşık beş dakika süreyle uygulanması önerilmektedir. Bunun yanı sıra bazı çalışmalarda kadınlar vajinal dilatatör kullanımını cinsel yaşamlarının doğasına müdahale olarak gördüklerini, bu araçların kullanımı sebebiyle kendilerini psikolojik ve duygusal açıdan rahatsız hissettiklerini ifade etmişlerdir. Bu sebeple her brakiterapi alan kadına rutinde vajinal dilatatörlerin kullanımının önerilmesi yerine profilaktik ve terapötik vajinal dilatatör tedavileri ayrı ayrı uygulanmalıdır. Vajinal uzunluk ölçümleri yapılmalı, kadınların cinsel işlev durumları değerlendirilmelidir (27).

Bakker ve ark. (2017) brakiterapiden sonra vajinada meydana gelen kısalma ve darlık sorunlarılla baş etmede hemşirenin vereceği cinsel danışmanlığın etkinliğini değerlendirmek amacıyla çalışma yapmışlardır. Sonuçta hemşireler tarafından verilen cinsel danışmanlık kadınların cinsel sorunlarını azaltmış, vajinal darlık sorunlarıyla baş etmede önerilen dilatatör kullanımı kadınlar tarafından daha fazla kabullenilmiştir (26).

Hemşirelerin jinekolojik kanserin tanı ve tedavisinin neden olduğu fiziksel ve psikolojik sorunları belirleme ve yol gösterme konusunda önemli sorumlulukları vardır. Hemşirelik rollerinin içinde danışmanlık öne çıkmaktadır. Hemşireler kendilerini cinsel danışmanlık konusunda yetersiz hissetmekte ve cinsel öykü alma konusunda güçlük yaşamaktadır. Danışmanlık hizmeti brakiterapi aşamasında çok önemlidir. Kadının, 
brakiterapiye yönelik sorunlarını ifade edebilmesi ve baş etme mekanizmalarını geliştirebilmesi bu süreçte verilebilecek danışmanlık hizmeti ile olanaklıdır $(28,29)$.

Kadınların yaşam kalitesinin önemli bir parçası olan cinsel yaşam, hemşirelik bakım alanlarından biridir. Sağlık ekibinin önemli bir üyesi olan hemşirelerin, brakiterapinin neden olduğu fiziksel ve psikolojik sorunları belirleme ve cinsel sorunları bulunan kadınlara yardım etmede önemli sorumlulukları vardır. Kadının cinsel yaşamı sorgulanırken bütüncül bakış açısı ile bakılmalıdır. Hemşirelerin cinsel sağlığı değerlendirmede güçlükler yaşadığı gözlenmektedir. Cinsel danışmanlık ve rehberlikte görüşmenin başlatılması zordur. Modellerin kullanılması görüşmenin başlatılmasına yardımcı olur $(30,31)$.

\section{Cinsel Danışmanlık}

Brakiterapi gören kadınların yaşam kalitelerinin yükseltilmesi ve sağlık bakımında bütünlüğün sağlanması için cinsellikle ilgili konularda danışmanlık verilmesi yararlı olmaktadır. Cinsel danışmanlık verebilmek için başta bireysel ve çift terapileri hakkında ayrıntılı eğitim alınmalıdır. Bu eğitimler kapsamında uygulamalı eğitim de olmalıdır (32). Dürüstlük, mahremiyet, gizlilik gibi konular ön planda tutulmalıdır. Danışanlar tarafından paylaşılan bilgiler duyarlılıkla dinlenmelidir. Danışan ile profesyonel bir boyutta görüşülmelidir. Çiftlere kimi zaman ev ödevleri verilebilir (33). Hemşirelerin bu süreçteki sorumlulukları, kadının cinsel gereksinimlerinin belirlenmesi, sorunları önlemeye yönelik girişimler planlama ve uygun yönde rehberlik yapmaktır. Kadına klinik değerlendirme öncesinde cinsel işlevlerine yönelik sorular sorma konuyu normalleştirerek kadını cinsel sorunlarını tartışma konusunda cesaretlendirir. Kadının cinsel yaşamının değerlendirildiği süreçte, cinsel ilişki sıklığı, cinsel istek boyutu, cinsel memnuniyet düzeyi, cinsel yönden endişeleri eşi ile samimiyeti ve iletişimi sorgulanmalıdır (34).

Hemşireler kadına yönelik cinsel sorunlarla başetme teknikleri oluştururken cinsel sorunlar ve üremeye ilişkin kaygılar konusunda somut bilgi ve beceriye sahip olmalıdır. Hemşireler cinsel konularla ilgili kendi inanç ve tutumlarının farkında olmalı, inanç ve tutumlarının cinselliğin tartışılması ve yaklaşımların belirlenmesinde engel oluşturmamasına dikkat etmelidir. Kadınlarla konuşurken etkin iletişim tekniklerinden yararlanmalı, kadın ile dostça ve destekleyici bir iletişim kurulmalıdır (35). Bunun yanında hemşireler kadınlara brakiterapinin cinsel işleve olan etkilerini anlatmalı, soruları yanıtlarken açık ve samimi olmalıdır. Kadının cinsel işlev ile ilgili endişelerini dinledikten sonra kadına endişe arttıkça cinsel olarak zevk alma ve arzunun azaldığı, endişeyi besleyen fikirlerin ortadan kaldırılması ve yalnızca cinsel birleşmeye yoğunlaşılmaması konusunda bilgi verilmelidir (36). Kadının cinsel fantezi kurması sağlanmalı, algılarının olumlu hale gelmesi için erotik düşünceleri ve fantezileri desteklenmelidir. Kadına, eşi ile evde beraber banyo yapmaları, aynı saatte yatağa girmeleri, beraber yemek yapmaları gibi, ilişkisini güçlendirecek ev ödevleri verilmelidir. Ayrıca cinsellik başlamadan önce, ön sevişmenin vajinal lubrikasyonu artırdığı, vajinal lubrikasyonun da cinsel ilişki sırasında ağrıyı azalttığı belirtilerek, ön sevişmenin uzun tutulmasının gerekli olduğu belirtilmelidir (37). Kadına mastürbasyonun cinsel hazzı artıran bir egzersiz olduğu, bu egzersizin vajinal lubrikasyonu artırdığı, çok sert olmadan yumuşak dairesel hareketlerle klitorise uygulanması gerektiği ve ilk aşamada kendisi tarafından yapılmasının faydalı olacağı belirtilmelidir. Bunun yanında disparoninin azaltılması için penetrasyonun daha az yaşandığı cinsel pozisyonlar anlatılmalıdır (38). Ayrıca penetrasyon esnasındaki ağrıyı azaltmak için su bazlı vajinal kayganlaştırıcı kullanabileceği ifade edilmelidir. Kadına, cinsel birleşme esnasında Kegel egzersizinin kadının düşüncelerini dış dünyaya kapatıp yalnızca perine kaslarına odaklanmasını sağlayacağı, cinsel hazzı ve uyarılmayı artıracağı belirtililerek, Kegel egzersizleri öğretilmelidir (39-41).

\section{Sonuç}

Cinsellik, çok boyutlu bir kavramdır ve jinekolojik kanser tanı ve tedavisi ile negatif yönde etkilenmektedir. Jinekolojik kanserin tedavi süreci içerisinde yer alan brakiterapi sonucunda vajina epitelinde elastikiyet kaybı, eritem, atrofi ve inflamasyon görülür. Işınlama sonucunda vajinada kuruluk ve daralma meydana gelir. Vajinadaki tüm bu değişimler sonucunda orgazm problemleri, elastikiyetin azalması ve disparoni sık görülmektedir. Jinekolojik kanser tedavisinin 
yanısıra kadın, kadınlık kimliğini, değerlerini, önceliklerini yeniden kazanma çabası içersindedir. Böyle bir süreçte, destek sistemleri ve danışmanlık hizmetleri kaygı ve endişeleri gidermede önemli rol oynamaktadır. Cinsel danışmanlık cinsellikle ilgili bilgi eksikliğinin giderilmesi, yanlış bilgilerin ve inançların düzeltilmesi, cinsel mitler hakkında bilgilendirme amacıyla danışanlara ya da çiftlere yardımcı olmaktır. Cinsel danışmanlıkta amaç, cinsel açıdan kadının korku ve endişesini azaltmak, kadının duygusal ve cinsel tepkisini artırmak, kadının eşine karşı öfkesini azaltmak, yeni duygusal ve cinsel teknikler denemek, eşler arasında iletişimi artırmak, cinsel ilişki sırasında dikkati dağıtan düşüncelerin dışlanmasını sağlamak ve kadının orgazm olma hakkındaki önyargılarını azaltmaktır. Bu nedenle cinsel danışmanlık, kadınların cinsel sorunlarını çözmede kullanabilen, cinsel yaşamlarını özgürleştiren ve kadının yaşam kalitesini artıran sihirli bir anahtardır.

iletişim: Çiğdem Bilge

E-posta: cigdemaydinbilge@gmail.com

\section{Kaynaklar}

1. Taylor TF. The origins of human sexual culture. Journal of Psychology ve Human Sexuality 2007;18 (2):69 -105.

2. Bozdemir N ve Özcan S. Cinselliğe ve cinsel sağlığa genel bakış. Turkish Journal of Family Medicine And Primary Care 2011; 5(4):37-46.

3. Karakoyunlu FB ve Öncel S. Cinsel fonksiyon bozukluklarında kadına ait hemşirelik bakım süreci örneği. Atatürk Üniversitesi Hemşirelik Yüksekokulu Dergisi 2009; 12(3):82-92.

4. Vaz AF, Pinto-neto AM, Conde DM, Paiva LC, Morais SS, Pedro AO, ve ark. Quality of life and menopausal and sexual symptoms in gynecologic cancer survivors: a cohort study. The Journal of The North American Menopause Society 2011; 18(6):662-9.

5. Serçekuş $P$ ve Türkcü SG. Jinekolojik kanserli hastalarda cinsellik. Dokuz Eylül Üniversitesi Hemşirelik Fakültesi Elektronik Dergisi 2015; 8(1):36-8.

6. Akkuzu G ve Ayhan A. Sexual functions of Turkish women with gynecologic cancer during the chemotherapy process. Asian Pacific Journal of Cancer Prevention 2013; 14(6):3561-4.

7. Gilbert E, Ussher JM ve Perz J. Sexuality after gynecologic cancer: a review of material, intrapsychic, and discursive aspects of treatment on women's sexual-wellbeing. Maturitas 2011; 70(1):42-57.

8. Hallaç $S$ ve Öz F. Genital kanser tanı sürecinde varoluşsal kaygı. Psikiyatride Güncel Yaklaşımlar 2011; 3(4):595-610.

9. Reis N, Beji NK, ve Coskun A. Quality of life and sexual functioning in gynecological cancer patients: results from quantitative and qualitative data. European Journal of Oncology Nursing 2010; 14 (2):137-46.

10. Abott-Anderson K ve Kwekkeboom KL. A systamatic review of sexual concerns reported by gynecological cancer survivors. Gynecologic Oncology 2012; 124(3): 477-89.

11. Pınar G, Algıer L, Çolak $M$ ve Ayhan A. Jinekolojik kanserli hastalarda yaşam kalitesi. Uluslararası Hematoloji-Onkoloji Dergisi 2008; 18(3):141-9.

12. Bilge Ç, Kaydırak $M$ ve Aslan E. Jinekolojik Kanserin Cinsel Yaşam Üzerindeki Etkileri. SDÜ Sağlık Bilimleri Enstitüsü Dergisi 2016; 7(3):31-8.

13. Goulet $D$, Danilack V ve Matteson KA. Enhanced recovery pathways for improving outcomes after minimally invasive gynecologic oncology surgery. Obstetrics ve Gynecology 2017; 129(1):207-8.

14. Kizir A ve Güvenli ME. Radyoterapinin ilkeleri. In: Can G (ed). Onkoloji Hemşireliği. İstanbul: Nobel Tıp Kitabevleri; 2014, 133- 145.

15. Şahin NH ve Bal MD. Üreme organ tümörleri. In: Beji NK (ed). Kadın Sağlığı ve Hastalıkları. 2nd edition. İstanbul: Nobel Tıp Kitabevleri; 2016, 204-219.

16. Small W Jr, Beriwal S, Demanes DJ, Dusenbery KE, Eifel P, Erickson B, ve ark. American Brachytherapy Society consensus guidelines for adjuvant vaginal cuff brachytherapy after hysterectomy. Brachytherapy 2012; 11:58-67.

17. Qian JM, Stahl JM, Young MR, Ratner E, Damast S. Impact of vaginal cylinder diameter on outcomes following brachytherapy for early stage endometrial cancer. Journal of Gynecologic Oncology 2017; 28(6):e84. doi: 10.3802/jgo.2017.28.e84.

18. Karaman Ş, Küçücük S ve Oral EN. Radyoterapide tedavi planlaması. In: Can G (ed). Onkoloji Hemşireliği. İstanbul: Nobel Tıp Kitabevleri; 2014, 147-153.

19. Kirchheiner K, Nout RA, Czajka-Pepl A, PonocnySeliger E, Sturdza AE, Dimopoulos, JC, Pötter R. Health related quality of life and patient reported symptoms before and during definitive radio (chemo) therapy using image-guided adaptive brachytherapy for locally advanced cervical cancer and early recovery-a mono-institutional prospective study. Gynecologic oncology 2015;136(3): 415-23. 
20. Çakar B, Karaca B ve Uslu R. Sexual dysfunction in cancer patients: a review. Journal of BUON 2013; 18(4):818-23.

21. Dinçer $M M$ ve Çolakerol A. İyatrojenik (medikal. cerrahi ve radyoterapi sonrası) cinsel işlev bozukluğular ve cinsel rehabilitasyon. Turkiye Klinikleri J Urology-Special Topics 2015; 8(3):37-9.

22. Karabuga $H$, Gultekin $M$, Tulunay $G$, Yuce $K$, Ayhan A, Yuce D, Yildiz, F. Assessing the quality of life in patients with endometrial cancer treated with adjuvant radiotherapy. International Journal of Gynecological Cancer 2015: 25(8);1526-33.

23. Cleary $\vee$ ve Hegarty J. Understanding sexuality in women with gynaecological cancer. European Journal of Oncology Nursing 2011; 15(1):38-45.

24. Cleary V, Hegarty J ve McCarthy G. Jinekolojik kanser teşhisi kadınların cinselliğini nasıl etkiliyor? Follow Cancer Nursing Practice 2013; 12(1): 32-7.

25. So WKW, Chui YY. Women's experience of internal radiation treatment for uterine cervical cancer. Journal of Advanced Nursing 2007; 60(2):154-61.

26. Bakker RM, Mens JW M, de Groot H. E, Tuijnman-Raasveld C, Braat C, Hompus Cvan Doorn HC. A nurse-led sexual rehabilitation intervention after radiotherapy for gynecological cancer. Supportive Care in Cancer 2017; 25(3):729-37

27. Miles T, ve Johnson N. Vaginal dilator therapy for women receiving pelvic radiotherapy. Cochrane Database Syst Rev 2014; 9.

28. Bitzer J, Platano G, Tschudin S, Alder J. Sexual counseling for women in the context of physical diseases: A teaching model for physicians. The Journal of Sexual Medicine 2011; 4(1):29-33.

29. Aydın S ve Beji NK. Infertil çiftlerde cinsel fonksiyon ve infertilite danışmanının rolü. Hemşirelikte eğitim ve Araştırma dergisi 2013; 10(2):8-13.

30. Açıkgöz F. Cinsel sağlığa yönelik hemşirelik yaklaşım modelleri. Androloji Bülteni 2011; 47:305-7.

31. Gölbaşı Z, Tuğut N, Erenel AŞ, Eroğlu K. Jinekoloji polikliniğine başvuran evli kadınlarda cinsel işlev bozukluğu yaygınlığı ve ilişkili bazı faktörler. Cumhuriyet Tıp Dergisi 2013; 36:1-10.
32. Zamani M, Tavoli A, Yazd KB, Sedighimornani N, Zafar M. Sexual therapy for women with multiple sclerosis and its impact on quality of life. Iran Journal of Psychiatry 2017; 12(1):58-65.

33. Parsa $P$, Tabesh RA, Soltani F ve Karami M. Effect of group counseling on quality of life among postmenopausal women in Hamadan, Iran. Journal of Menopausal Medicine 2017; 23(1): 49-55.

34. Oskay Ü. Cinsellik ve üreme sorunları. In: Can G (ed). Onkoloji Hemşireliği, İstanbul: Nobel Tıp Kitabevi; 2014, 497-515.

35. Malary $M$, Pourasghar $M$, Khani $S$, Moosazadeh $M$ ve Hamzehgardeshi Z. Psychometric properties of the sexual interest and desire inventory-female for diagnosis of hypoactive sexual desire disorder: The Persian version. Iranian Journal of Psychiatry 2016; 11(4):262-8.

36. Weeks GR ve Hertlein KM. Hypoactive sexual desire disorder treatment. In: Hertlein KM Weeks GR ve Gambescia N (eds). Systemic Sex Therapy. New York: Routledge; 2015, 52-85.

37. Pyke $R$ ve Clayton $A$. What sexual behaviors relate to decreased sexual desire in women? a review and proposal for end points in treatment trials for hypoactive sexual desire disorder. Sexual Medicine 2016; doi: 10.1016/j.esxm.2016.11.003.

38. Wylie KR ve Jones RH. Inhibited arousal in women. In: Hertlein KM Weeks GR ve Gambescia N (eds). Systemic Sex Therapy. New York: Routledge; 2015, 152-168.

39. McCabe M. Female orgasmic disorder. In: Hertlein KM Weeks GR ve Gambescia N (eds). Systemic Sex Therapy. New York: Routledge; 2015, 171186.

40. Mitchell KR, Geary R, Graham CA, Datta J, Wellings $K$, Sonnenberg $P$ ve ark. Painful sex (dyspareunia) in women: prevalence and associated factors in a British population probability survey. BJOG: An International Journal of Obstetrics ve Gynaecology 2017; doi: 10.1111/1471-0528.14518.

41. Nappi RE, Cucinella L, Martella S, Rossi M, Tiranini $L$ ve Martini E. Female sexual dysfunction (FSD): Prevalence and impact on quality of life (QoL). Maturitas 2016; 94:87-91. 